Perceptual \& Motor Skills: Motor Skills \& Ergonomics

2013, 116, 3, 1-13. (C) Perceptual \& Motor Skills 2013

\title{
MENTAL TOUGHNESS OF MIXED MARTIAL ARTS ATHLETES AT DIFFERENT LEVELS OF COMPETITION ${ }^{1}$
}

\author{
MARK A. CHEN AND DAVID J. CHEESMAN \\ School of Social Sciences and Law \\ University of Teesside
}

\begin{abstract}
Summary.-This study investigated whether mental toughness distinguishes mixed martial arts (MMA) athletes competing at different levels. It was theorized that higher mental toughness would separate those competing at the professional level compared to lower levels. Male MMA competitors $(N=136, M$ age $=27.1 \mathrm{yr}$., $S D=4.8$ ) were categorized as amateur, semi-professional, or professional and assessed by questionnaire using the Psychological Performance Inventory-A and the Sports Mental Toughness Questionnaire. There were statistically significant differences between the three groups on mental toughness. The professional group had higher scores compared to semi-professional and amateur groups with regard to confidence, positive cognition, and determination. The findings supported previous work that athletes performing at higher levels have superior mental toughness.
\end{abstract}

Mental toughness has often been cited as being the crucial psychological attribute for explaining differences in athletic performance (see Clough, Earle \& Sewell, 2002; Bull, Shambrook, James, \& Brooks, 2005; Crust, 2007, 2008; Connaughton, Hanton, Jones, \& Wadey, 2008; Gucciardi, Gordon, \& Dimmock, 2009). The construct has been measured in terms of the model offered by Sheard, Golby, \& van Wersch (2009), which includes three traits: confidence, constancy, and control. Confidence is the belief in achieving the desired outcome in competition, despite personal or competition-specific distractions and irrespective of the performer's actual competence. Constancy reflects an athlete's determination to meet the demands of competition, willingness to take responsibility for setting competition goals, and ability to concentrate. Control is being able to maintain focus despite physical or emotional pain and unexpected, uncontrollable events.

Mental toughness overlaps with the similar construct of hardiness (e.g., Sheard, 2009; Sheard \& Golby, 2010), but is distinguished from it by the confidence construct, which is necessary for optimal sport performance (Clough, et al., 2002). This distinction is important as hardy individuals may not necessarily have enough confidence to compete, whereas mentally tough individuals relish challenging themselves in competition. This is critical to Sheard's (2010) interpretation that mental toughness is not mere reaction to adverse situations, but the positive psychological trait motivating one to excel.

${ }^{1}$ Address correspondence to Dr. Mark Chen, School of Social Sciences and Law, University of Teesside, Middlesbrough, TS1 3BA, England, or e-mail (m.chen@tees.ac.uk). 
There have been few attempts until recently to evaluate mental toughness differences between athletes at different levels within the same sport. Dongsung and Kang-Heon (1994) explored mental toughness among 223 elite and non-elite female athletes in volleyball, badminton, table tennis, archery, and shooting. They found that elite athletes had higher overall mental toughness (Cohen's $d=0.57$ ) including imagery control, confidence, motivation, and positive energy. Nicholls, Polman, Levy, and Backhouse (2009) did not find evidence to support the assertion that athletes with higher achievement have higher mental toughness, but acknowledged the small number of elite participants $(N=60)$ recruited compared to university participants $(N=289)$. Golby, Sheard, and Lavelle (2003) sampled 70 international rugby league players and found no significant differences between the best teams in mental toughness, though differences were found in hardiness.

In a follow up study, Golby and Sheard (2004) examined 115 professional rugby league players at three different playing standards (international, super league, and division one). They found that international-level players were characterised by the highest hardiness (Cohen's $d$ range $=$ 1.67-2.13) as measured by commitment, control, and challenge. Sheard (2009), using the Alternative Psychological Performance Inventory, investigated mental toughness differences between team members from Australia and Great Britain prior to the 2006 international rugby tournament and found the Australian winners to have statistically significantly higher scores in positive cognition, visualization, total mental toughness, and challenge compared to Great Britain's team members (Cohen's $d$ range $=$ 1.4-2.0). Sheard and Golby (2010) found that trait hardiness differentiated international competitors from those competing at sub ordinate levels. The authors acknowledged that the influence of hardiness on competitive sport performance appears moderate (ES range $=0.48-0.89$ ). For this reason the current paper focused on mental toughness rather than hardiness, due to its greater breadth of relevance to sport competition.

Finally, Crust and Azadi (2010) found that athletes competing at regional levels and above reported statistically significantly higher mental toughness than club/ university athletes (Cohen's $d=0.45$ ).

Mixed martial arts is a modern sport that offers an interesting perspective from which to examine the hypothesis that those with greater mental toughness rise to meet the demands of higher levels of competition. No previous research has investigated the psychological aspect of mixed martial arts, with the relatively few published studies being sociological (Hirose \& Pih, 2009; Spencer, 2009; Garcia \& Malcolm, 2010) or physiological (Dabbs, Schick, Beam, Brown, Coburn \& Schick, 2010; Lenetsky \& Harris, 2012). Because mixed martial arts in the United Kingdom has no 
standardized and progressively structured championships, individuals are free to compete at whatever level they desire. Therefore the main difference between the three levels of mixed martial arts has been the rules of the competition and the extra psychological demands these entail. Professional rules matches are longer, allow a variety of head strikes with hand, knee, and elbow, both standing and on the ground, as well as a wide range of joint locks (Association of Boxing Commissions, 2011). The semi-professional matches are shorter and the more dangerous aspects of the sport that are crucial to the professional matches, such as ground-and-pound techniques and rotational knee locks, are disallowed. Finally, the amateur rules disallow strikes to the head and combatants often have to wear additional protective equipment. Matches are sometimes limited to one 5-min. round (UK MMA League, 2009).

The model of mental toughness offered by Sheard, et al. (2009) provides a means of understanding the psychological demands of mixed martial arts at the highest level, as the constructs of confidence, constancy, and control are those most closely related to sporting performance, compared to other constructs measured in alternative mental toughness models (e.g., Clough, et al., 2002). The potential threats and increased competition at the professional ranks is greater than at the other two levels, therefore professional performers would be expected to have superior confidence. Recent work (Crust \& Keegan, 2010) has found Ability Confidence to be significantly related to attitudes toward physical risk. The additional physical risk inherent at the professional ranks would require more emotional control and focus to avoid injury or defeat. Also, greater constancy would be needed to cope with the higher physical and mental demands placed on competitors in training and preparation.

These key qualities can be measured using the Sports Mental Toughness Questionnaire (SMTQ; Sheard, et al., 2009) and the Alternative Psychological Performance Inventory (PPI-A; Golby, Sheard, \& van Wersch, 2007). The main purpose of this study was to use these measures to establish whether a difference in mental toughness can be demonstrated at the three different strata of mixed martial arts in the United Kingdom. A secondary aim of the study was to examine the convergent validity between the two different measures of mental toughness. Gucciardi (2012) recently found some support for the convergent validity of the PPI-A in relation to Achievement Goals. The PPI-A subscales were most strongly related with MAp goals, although the correlations were small to moderate $(r=.42$, $r=.20, r=.35, r=.33$ for MAp correlations with Determination, Self-Belief, Positive Cognition, and Visualisation, respectively). It was hypothesized in accordance with previous research (e.g., Dongsung \& Kang-Heon, 1994; Golby \& Sheard, 2004; Sheard, 2009), the professional group's total mean 
scores on mental toughness and also scores on individual subscales would be statistically significantly higher compared to those of semi-professional and amateur groups. Additionally, moderate positive correlations among the subscales of the two inventories were expected.

\section{METHOD}

\section{Participants}

The initial convenience sample for this study consisted of 158 male participants, 136 of whom met the inclusion criteria, ranging in age from 18 to 42 years $(M=27.2, S D=4.8)$. The two inclusion criteria were (1) having competed in an organised mixed martial arts competition within the last 12 months and (2) participating in at least two fights at the level they represented. The final participants were participating under the three competitive rule structures that have been used in contemporary mixed martial arts in the UK, namely amateur $(N=48 ; M$ age $=26.8, S D=4.0$, range $=18-35)$, semi-professional $(N=39 ; M$ age $=25.6, S D=4.9$, range $=$ $18-42)$, and professional $(N=49 ; M$ age $=28.9, S D=4.9$, range $=20-41)$.

\section{Measures of Mental Toughness (Appendix, p.・•)}

The Alternative Psychological Performance Inventory (PPI-A; Golby, et al., 2007) is a revised version of Loehr's (1986) original mental toughness measures. It is a 14-item questionnaire yielding a total Mental Toughness score and four subscale scores: Determination, Self-belief, Positive cognition, and Visualization. Participants rated the items on a five-point Likerttype scale with anchors 1: Almost always and 5: Almost never. Golby, et al. (2007) applied factor analysis to the original Psychological Performance Inventory to identify these four factors and confirm the existence of a general mental toughness factor. Cronbach alphas for the four subscales indicate acceptable internal consistency (Kline, 2005); for Determination $\alpha=$ .72 , for Self-belief .75, for Positive cognition .75, and for Visualisation .78. The PPI-A has not been used extensively, so as part of the process of construct validation it is important to compare it to a frequently used inventory. The Sports Mental Toughness Questionnaire (SMTQ) was chosen as the criterion measure on the basis that it is a more established measure of mental toughness that also has a control subscale.

The SMTQ is also a 14-item self-report, which yields a total mental toughness score and three subscale scores: Confidence, Constancy, and Control. Participants rated the items on a four-point Likert-type scale with anchors A: Not at all true and D: Very true. Sheard, et al. (2009) constructed this questionnaire using exploratory and confirmatory factor analysis of the key factors that had been attributed to mental toughness in the literature. Cronbach's alphas for the three factors were acceptable (Kline, 2005); for Confidence $\alpha=.79$, for Control .72, and for Constancy .76. There is also 
preliminary support for the factor structure, reliability and validity of this measure (Sheard, et al., 2009).

\section{Procedure}

Following approval from the University of Teesside Board of Ethics, participants were gathered using three approaches: (1) mixed martial arts forum posting, (2) an online survey, and (3) attending events. All procedures were conducted in line with the British Psychological Society's Code of Ethics and Conduct.

Mixed martial arts forum posting. - The main UK forum, Cage Warriors, was used for recruitment (http://www.cagewarriors.com/forums). The Cage Warriors forum has the highest number of registered users (approximately 20,000) of any UK MMA forum. Once contact had been made, interested parties were e-mailed a packet comprising an information sheet, a demographic questionnaire including specific items to identify age, record, and martial arts background, the PPI-A, and the SMTQ. The participants were naïve to the research aims and the two questionnaires were counterbalanced by having two versions of the packet and noting which packet was sent last, to alternate the administration order.

Online survey. - Using specialist software (Survey Monkey) the above four sheets (information sheet and instructions, participant sheet and the PPI-A and SMTQ) were made accessible through a web link. The web site address was then distributed via forum posts. The participants were asked to read the information sheet first and to contact the investigator should they have any questions.

Attending events. - Five mixed martial arts events throughout the country were attended, following being granted permission from the organizers of each of the shows. Where possible, the organizers arranged for a researcher to address the coaches and competitors present to explain the nature of the study and ask for participation. Envelope packets with hard-copy versions of the survey packet and pens were given to willing participants. Once completed, the packets were handed back to the chief investigator who provided a debriefing sheet and thanked them for their participation. The packets were prepared in counterbalanced order prior to their administration.

\section{Analysis}

Initial data checks showed the dependent variables met the assumptions of homogeneity of variance and normal distribution. Data were analysed using a multivariate analysis of variance (MANOVA) with follow-up analyses of variance (ANOVAs). Initial data analysis used the method of recruitment as an independent variable to confirm no differences across the different methods so the data could be pooled. Therefore, competition 
status with three levels (i.e., professional, semi-professional, or amateur) served as the independent variable while the seven mental toughness subscales from the PPI-A and SMTQ acted as the dependent variables. Follow-up univariate analyses with post hoc comparisons were used to identify sources of statistically significant differences. Eta-squared was used as the estimate of effect size. The alpha level was set at .05. Statistical analysis was conducted using SPSS for Windows, Version 16.0 (SPSS, Inc., Chicago, IL).

\section{RESULTS}

With method of recruitment as the independent factor with three levels (online survey $N=66$, event $N=57$, forum $N=13$ ), the MANOVA was statistically significant $\left(F_{14,256}=5.14, p<.05, \eta^{2}=0.22\right)$. Separate individual ANOVAs were run on each dependent variable (all variables had acceptable homogeneity of variance apart from Confidence). There were no statistically significant effects of recruitment method for Determination, Positive cognition, Visualisation, Control, or Constancy. Statistically significant effects were observed for Confidence $\left(F_{2,133}=18.49, p<.001\right.$, partial $\left.\eta^{2}=0.22\right)$, Self-belief $\left(F_{2,133}=10.55, p<.001\right.$, partial $\left.\eta^{2}=0.14\right)$, the total PPI-A score $\left(F_{2,133}=3.85, p<.05\right.$, partial $\left.\eta^{2}=0.06\right)$ and SMTQ scores $\left(F_{2,133}=8.07, p<.001\right.$, partial $\left.\eta^{2}=0.11\right)$. All these results indicated the mean scores for the online survey were lower than means obtained from both the event and forum methods of recruitment.

Regarding differences between competition status (professional, semiprofessional, and amateur), the descriptive statistics for the seven subscales and total scores for both mental toughness inventories are presented in Table 1. Using Wilks $\lambda$, MANOVA results yielded a statistically significant overall effect $\left(F_{14.256}=1.99, p<.05\right.$, partial $\left.\eta^{2}=0.10\right)$. Each dependent variable was followed up with individual ANOVAs and statistically significant effects were found for three of the subscales using a corrected Bonferonni cutoff value of $p \leq .007$ to protect against Type I error (Tabachnick \& Fidell, 2007). ANOVA results yielded moderate-sized effects for Determination $\left(F_{2,133}=5.18, p=.007\right.$, partial $\left.\eta^{2}=0.07\right)$, Positive cognition $\left(F_{2,133}=8.80\right.$, $p<.001$, partial $\left.\eta^{2}=0.12\right)$, and Confidence $\left(F_{2,133}=8.93, p<.001\right.$, partial $\eta^{2}=$ 0.12). Determination, Positive cognition, and Confidence scores were all statistically significantly higher in the professionals compared to the other two groups. A separate MANOVA on the total PPI-A and total SMTQ scores was statistically significant $\left(F_{4,266}=4.47, p<.005\right.$, partial $\left.\eta^{2}=0.06\right)$. Univariate ANOVAs yielded statistically significant effects for both PPI-A $\left(F_{2,133}=\right.$ 8.56, $p<.005$, partial $\left.\eta^{2}=0.11\right)$ and SMTQ $\left(F_{2,133}=5.30, p<.01\right.$, partial $\eta^{2}=$ 0.07 ), with the professional group scoring statistically significantly higher than the semi-professional and amateur group on both questionnaires. 
TABLE 1

Descriptive Statistics for PPI-A Subscales and Total Scores and SMTQ Subscales and Total Scores of Professional, Semi-professional, and Amateur Groups

\begin{tabular}{|c|c|c|c|c|c|c|c|}
\hline \multirow{3}{*}{ Measure } & \multicolumn{7}{|c|}{ Competition Level } \\
\hline & \multicolumn{2}{|c|}{ Amateur } & \multicolumn{2}{|c|}{ Semi-professional } & \multicolumn{2}{|c|}{ Professional } & \multirow{2}{*}{ Range } \\
\hline & $M$ & $S D$ & $M$ & $S D$ & $M$ & $S D$ & \\
\hline \multicolumn{8}{|l|}{ PPI-A } \\
\hline Determination & 12.56 & 1.62 & 12.54 & 1.80 & $13.51^{\ddagger}$ & 1.60 & $7-15$ \\
\hline Self-belief & 14.02 & 3.18 & 14.36 & 3.00 & 15.61 & 2.55 & $6-20$ \\
\hline Positive cognition & 15.90 & 2.47 & 15.54 & 2.37 & $17.37^{\dagger}$ & 1.78 & $10-20$ \\
\hline Visualisation & 12.31 & 2.56 & 12.13 & 2.99 & 13.41 & 1.99 & $3-15$ \\
\hline Total score & 54.79 & 7.56 & 54.57 & 8.05 & $59.90^{\dagger}$ & 5.43 & $37-68$ \\
\hline \multicolumn{8}{|l|}{ SMTQ } \\
\hline Confidence & 15.48 & 3.36 & 16.10 & 3.75 & $18.39^{\dagger}$ & 3.12 & $9-24$ \\
\hline Control & 10.50 & 2.46 & 10.41 & 1.93 & 10.63 & 2.64 & $5-16$ \\
\hline Constancy & 13.23 & 2.46 & 13.44 & 1.92 & 13.78 & 1.86 & $10-16$ \\
\hline Total score & 39.21 & 5.62 & 39.95 & 5.62 & $42.80^{*}$ & 5.64 & $28-54$ \\
\hline
\end{tabular}

Note.-Mean scores of Professional group marked as statistically significantly different from other groups at ${ }^{*} p<.01,{ }^{\star} p<.001,{ }^{\star} p=.007$.

Pearson product-moment correlations revealed small to medium correlations (cf. Cohen, 1988, pp. 79-81) among all of the subscales of the PPI-A and SMTQ inventories (Table 2). With the exception of the correlations of Visualisation with Control and Constancy, all of the other subscales of the PPI-A and the SMTQ showed statistically significant $(p<.01)$, small to medium correlations. The highest correlation among the subscales was between Confidence and both Self-belief $(r=.63)$ and Positive cognition $(r=.63)$. There was also a strong correlation within the PPI-A between Self-belief and Positive cognition $(r=.68)$.

\section{DisCUSSION}

The main purpose of this study was to investigate whether mental toughness would distinguish the competitive level at which the MMA athletes had chosen to compete. The results showed that certain subscales of the inventories did indeed discriminate between the competitor's status, with statistically significant results being obtained on Determination, Positive cognition (PPI-A), and Confidence (SMTQ), thus supporting the hypothesis. The PPI-A showed professionals to have on average $9.8 \%$ higher Mental Toughness scores than semi-professional competitors and 9.3\% higher than amateur athletes. For the SMTQ, these values were 7.1\% and $9.1 \%$, respectively. The finding that Determination separated the professionals from the amateurs and semi-professionals is similar to previous findings that commitment increases with higher levels of competition (Golby \& Sheard, 2004; Sheard \& Golby, 2010). 
TABLE 2

INTER-CORRELATIONS OF PPI-A AND SMTQ SUBSCALES WitH 95\% CONFIDENCE INTERVALS

\begin{tabular}{|c|c|c|c|c|c|c|}
\hline & 1 & 2 & 3 & 4 & 5 & 6 \\
\hline \multicolumn{7}{|l|}{ 1. Determination } \\
\hline 2. Self-belief & $\begin{array}{c}.36^{\dagger} \\
(.20, .50)\end{array}$ & & & & & \\
\hline 3. Positive cognition & $\begin{array}{c}.54^{\dagger} \\
(.41, .65)\end{array}$ & $\begin{array}{c}.64^{\dagger} \\
(.53,73)\end{array}$ & & & & $\bar{\equiv}$ \\
\hline 4. Visualization & $\begin{array}{c}.37^{\dagger} \\
(.22, .51)\end{array}$ & $\begin{array}{c}.36^{\dagger} \\
(.20, .50)\end{array}$ & $\begin{array}{c}.44^{\dagger} \\
(.29, .57)\end{array}$ & & & \\
\hline 5. Confidence & $\begin{array}{c}.50^{\dagger} \\
(.36, .62)\end{array}$ & $\begin{array}{c}.68^{\dagger} \\
(.58, .76)\end{array}$ & $\begin{array}{c}.61^{\dagger} \\
(.49, .71)\end{array}$ & $\begin{array}{c}.40^{\dagger} \\
(.25, .53)\end{array}$ & & \\
\hline 6. Control & $\begin{array}{c}.22^{\dagger} \\
(.05, .38)\end{array}$ & $\begin{array}{c}.33^{\dagger} \\
(.17, .47)\end{array}$ & $\begin{array}{c}.37^{\dagger} \\
(.21, y)\end{array}$ & $\begin{array}{c}.17^{*} \\
(.00, .33)\end{array}$ & $\begin{array}{c}.17^{*} \\
(.00, .33)\end{array}$ & \\
\hline 7. Consistency & $\begin{array}{c}.45^{\dagger} \\
(.31, .58)\end{array}$ & $\begin{array}{c}.32^{\dagger} \\
(.16, .46)\end{array}$ & $\begin{array}{c}.47^{\dagger} \\
(.34, .68)\end{array}$ & .16 & $\begin{array}{c}.38^{\dagger} \\
(.23, .52)\end{array}$ & $\begin{array}{c}.33^{\dagger} \\
(.17, .47)\end{array}$ \\
\hline
\end{tabular}

${ }^{*} p<.05 .{ }^{\natural} p<.01$.

This study supported the idea that confidence may be a vital attribute distinguishing those who compete at higher levels. This increased confidence could result in the willingness of those in the professional mixed martial arts ranks to take greater physical risks compared to those in the less dangerous amateur and semi-professional ranks, as physical risk has been found to be correlated $(r=.21, p<.05)$ with Ability Confidence (Crust \& Keegan, 2010). This is despite the online survey being taken by up to half of the sample and producing statistically significantly lower scores compared to the forum and event methods.

The importance of determination and confidence may be speculated to increase approach-related behaviour for all aspects of involvement in the sport. In this sense, determination can be seen as a willingness to engage in problem-solving coping strategies to deal with the stressors of competition or training. As this construct represents the individual's dedication and commitment, it can be interpreted that professional mixed martial arts competition requires a superior amount of these resources to cope with the increased demands of the environment. Crust and Azadi (2010) also found that commitment was related to the most use of psychological performance strategies among athletes from football, netball, tennis, and athletics.

Positive cognition scores also differentiated the professional-level athletes from both amateurs and semi-professionals. This compares favourably with Sheard (2009) who found positive cognition and total mental toughness to differentiate team members of the 2006 tournament winners from Australia and their competitors from Great Britain. This factor has been said to 
reflect the athletes' capacity to be positive, maintain a sense of enjoyment, and thrive in adversity (Golby, et al., 2007). Gucciardi, et al., (2008) found support for the importance of positive cognition and the ability to override negative thoughts as a central component of mental toughness. Also, the idea that positive emotions and cognitions facilitate adaptive coping and adjustment to acute stress is documented in a number of studies (Tugade, Fredrickson, \& Barrett, 2004). The athletes who choose to compete in professional mixed martial arts may have had more positive expectations, as they were more confident in their abilities to cope with the contest and held greater optimism towards the outcomes of the competition.

\section{Validity}

A secondary aim of the study was to establish convergent validity between the PPI-A and SMTQ. The convergent validity data showed mixed results. Some subscales showed evidence for convergence, including moderate correlations between Confidence, Self-belief, and Positive cognition. However, the total Mental Toughness scores showed some divergence between inventories, with amateurs scoring slightly higher than semi-professionals on the PPI-A. Therefore these results are not entirely supportive of recent attempts (Gucciardi, 2012) to validate the PPI-A.

\section{Limitations and Conclusions}

Limitations of the present study include the self-selected sample collected online and via forum postings. There was also some evidence regarding a possible saliency priming between the three methods of recruitment, which demonstrably affected the results: Confidence scores in the online method were statistically significantly lower compared to the event and forum recruitment methods. This suggests that future studies should recruit participants to complete questionnaires as closely, as possible to a competition performance to provide the most valid measure of competitive confidence. There is also a further limitation regarding the convenience sample of events attended, although this likely did not affect results.

In general, traits of confidence, positive cognition, determination, and higher mental toughness were found to be as much as $10 \%$ higher in mixed martial arts athletes competing at the professional level compared to participants at lower levels of competition. There was a minor inconsistency in that professionals had higher "mental toughness" compared to semi-professional competitors, and higher than amateurs, but by a smaller margin on the PPI-A. Amateurs, it appears, have higher "mental toughness" than semi-professionals on the PPI-A. This result was unexpected, but invites further research into the relationship of mental toughness, coping strategies, and the goals competitors set for themselves by participants to compete at the different competitive levels. 


\section{REFERENCES}

Association of Boxing Commissions. (2011) Unified rules of MMA. Retrieved from http:/ / www.abcboxing.com/unified_mma_rules.

Bull, S. J., Shambrook, C. J., James, W., \& Brooks, J. E. (2005) Towards an understanding of mental toughness in elite cricketers. Journal of Applied Sport Psychology, 17, 209-227.

Cagewarriors Fighting Championship. (2008) Cagewarriors forum. Retrieved from http:/ / www.cagewarriors.com/forums.

Clough, P., Earle, K., \& Sewell, D. (2002) Mental toughness: the concept and its measurement. In I. Cockerill (Ed.), Solutions in Sport Psychology. London: Thompson. Pp. 32-45.

CoHen, J. (1988) Statistical power analysis for the behavioural sciences. (2 ${ }^{\text {nd }}$ ed.) New York, New York: Academic Press.

Connaughton, D., Hanton, S., Jones, G., \& Wadey, R. (2008) Mental toughness research: key issues in this area. International Journal of Sport Psychology, 39, 192-204.

CRUST, L. (2007) Mental toughness in sport: a review. International Journal of Sport $\mathcal{E}$ Exercise Psychology, 5(3), 270-290.

CRust, L. (2008) A review and conceptual re-examination of mental toughness: implications for future researchers. Personality and Individual Differences, 45, 576-583.

CRust, L., \& AzADI, K. (2010) Mental toughness and athletes use of psychological strategies. European Journal of Sport Science, 10(1), 43-51.

Crust, L., \& Keegan, R. (2010) Mental toughness and attitudes to risk-taking. Personality and Individual Differences, 49, 3, 164-168.

Dabbs, N. C., Schick, M. G., Beam, W. C., Brown, L. E., Coburn, J. W., \& Schick, E. E. (2010) Physiological profile of mixed martial artists. Medicina Sportiva, 14, 182-187.

DongsunG, S. S., \& KanG-Heon, L. (1994) A comparative study of mental toughness between elite and non-elite female athletes. Korean Journal of Sport Science, 6, 85-102.

GaRCiA, R. S., \& Malcolm, D. (2010) Decivilizing, civilizing or informalizing? The international development of mixed martial arts. International Review for the Sociology of Sport, 45, 39-58.

Golby, J., \& SheArD, M. (2004) Mental toughness and hardiness at different levels of rugby league. Personality and Individual Differences, 37, 933-942.

Golby, J., Sheard, M., \& Lavallee, D. (2003) A cognitive-behavioural analysis of mental toughness in national rugby league football teams. Perceptual \& Motor Skills, 96, 455-462.

Golby, J., Sheard, M., \& VAN Wersch, A. (2007) Evaluating the factor structure of the Psychological Performance Inventory. Perceptual \& Motor Skills, 105, 309-325.

GuCCIARDI, D. F. (2012) Measuring mental toughness in sport: a psychometric examination of the Psychological Performance Inventory-A and its predecessor. Journal of Personality Assessment, 94(4), 393-403.

Gucciardi, D. F., Gordon, S., \& DimMOCK, J. A. (2008) Towards an understanding of mental toughness in Australian football. Journal of Applied Sport Psychology, 20, 261-281.

Gucciardi, D. F., Gordon, S., \& Diммоск, J. A. (2009) Advancing mental toughness research and theory using personal construct psychology. International Review of Sport \& Exercise Psychology, 2(1), 54-72. 
Hirose, A., \& Pih, K. K. (2009) Men who strike and men who submit: hegemonic and marginalized masculinities in mixed martial arts. Men and Masculinities, 13(2), 190-209.

KLINE, R. B. (2005) Principles and practice of structural modelling. (2 ${ }^{\text {nd }}$ ed.) New York: Guilford.

LENETSKY, S., \& HARRIS, N. (2012) The mixed martial arts athlete: a physiological profile. Strength and Conditioning Journal, 34(1), 32-47.

LoeHr, J. E. (1986) Athletic excellence: mental toughness training for sports. New York: Plume.

ML Sports,Ltd. (2011) MMA universe. Retrieved from http:/ / www.mmauniverse.com/.

Nicholls, A. R., Polman, R. C. J., Levey, A. R., \& Backhouse, S. H. (2009) Mental toughness in sport: achievement, gender, age, experience, and sport type differences. Personality and Individual Differences, 47, 73-75.

SHEARD, M. (2009) A cross-national analysis of mental toughness and hardiness in elite university rugby league teams. Perceptual E Motor Skills, 109, 213-223.

SHEARD, M. (2010) Mental toughness: the mindset behind sporting achievement. London: Routledge.

SheARD, M., \& Golby, J. (2010) Personality hardiness differentiates elite-level sport performers. International Journal of Sport and Exercise Psychology, 8, 160-169.

Sheard, M., Golby, J., \& van Wersch, A. (2009) Progress toward construct validation of the Sports Mental Toughness Questionnaire (SMTQ), European Journal of Psychological Assessment, 25, 186-193.

SPENCER, D. C. (2009) Habit(us), body techniques and body callusing: an ethnography of mixed martial arts. Body \& Society, 15, 119-143.

TABAchnick, B. G., \& Fidell, L. S. (2007) Using multivariate statistics. (5 ${ }^{\text {th }}$ ed.) London: Pearson.

Tugade, M. M., Fredrickson, B. L., \& Barrett, L. F. (2004) Psychological resilience and positive emotional granularity: examining the benefits of positive emotions on coping and health. Journal of Personality, 72(6), 1161-1190.

UK MMA League. (2009) Rules Overview. UK MMA League. Retrieved from http:/ / www.mmaleague.tv/.

Accepted April 17, 2013. 


\section{Appendix: Questionnaires}

Please circle only one response for each item. Select whichever one best fits your interpretation of the item as it relates to you in sport. Be as open and honest as you can with yourself and respond to each item as it pertains to you now. Thank you.

\begin{tabular}{|c|c|c|c|c|c|c|}
\hline & $\begin{array}{l}\text { Paraphrased Item from } \\
\text { Alternative Psychologi- } \\
\text { cal Performance Inven- } \\
\text { tory (PPI-A: Golby, } \\
\text { et al., 2007) }\end{array}$ & $\begin{array}{l}\text { Almost } \\
\text { ALWAYS }\end{array}$ & Often & SOMETIMES & Seldom & $\begin{array}{l}\text { ALMOST } \\
\text { NEVER }\end{array}$ \\
\hline 1 & $\begin{array}{l}\text { Goals keep me } \\
\text { working hard. }\end{array}$ & 5 & 4 & 3 & 2 & 1 \\
\hline 2 & $\begin{array}{l}\text { Don't have to be } \\
\text { pushed }\end{array}$ & 5 & 4 & 3 & 2 & 1 \\
\hline 3 & $\begin{array}{l}\text { Willing to give } \\
\text { whatever it takes }\end{array}$ & 5 & 4 & 3 & 2 & 1 \\
\hline 4 & $\begin{array}{l}\text { Lose confidence } \\
\text { quickly }\end{array}$ & 1 & 2 & 3 & 4 & 5 \\
\hline 5 & $\begin{array}{l}\text { Keep strong positive } \\
\text { emotion }\end{array}$ & 5 & 4 & 3 & 2 & 1 \\
\hline 6 & Positive thinker & 5 & 4 & 3 & 2 & 1 \\
\hline 7 & Negative self-talk & 1 & 2 & 3 & 4 & 5 \\
\hline 8 & $\begin{array}{l}\text { Clear interfering } \\
\text { emotion }\end{array}$ & 5 & 4 & 3 & 2 & 1 \\
\hline 9 & $\begin{array}{l}\text { Genuine sense of joy } \\
\text { and fulfilment }\end{array}$ & 5 & 4 & 3 & 2 & 1 \\
\hline 10 & $\begin{array}{l}\text { Change negative } \\
\text { moods }\end{array}$ & 5 & 4 & 3 & 2 & 1 \\
\hline 11 & $\begin{array}{l}\text { Turn crisis into } \\
\text { opportunity }\end{array}$ & 5 & 4 & 3 & 2 & 1 \\
\hline 12 & Mentally practice & 5 & 4 & 3 & 2 & 1 \\
\hline 13 & Thinking in pictures & 5 & 4 & 3 & 2 & 1 \\
\hline 14 & $\begin{array}{l}\text { I visualise working } \\
\text { through tough } \\
\text { situations prior } \\
\text { to competition. }\end{array}$ & 5 & 4 & 3 & 2 & 1 \\
\hline
\end{tabular}

This is not a test. Please answer each question by circling the letter that best describes how you are generally. Thank you. 


\begin{tabular}{|c|c|c|c|c|c|}
\hline & $\begin{array}{l}\text { Paraphrased Item from Sports } \\
\text { Mental Toughness Questionnaire } \\
\text { (SMTQ: Sheard, et al., 2009) }\end{array}$ & $\begin{array}{l}\text { Not AT } \\
\text { ALL TRUE }\end{array}$ & $\begin{array}{l}\text { A LitTle } \\
\text { TRUE }\end{array}$ & $\begin{array}{c}\text { Mostly } \\
\text { TRUE }\end{array}$ & $\begin{array}{l}\text { VERY } \\
\text { TRUE }\end{array}$ \\
\hline 1 & Unshakeable confidence & A & B & $\mathrm{C}$ & $\mathrm{D}$ \\
\hline 2 & Anxiety from unexpected & A & B & C & $\mathrm{D}$ \\
\hline 3 & Committed to completing tasks & A & B & C & $\mathrm{D}$ \\
\hline 4 & Worry about performing poorly & A & B & $\mathrm{C}$ & $\mathrm{D}$ \\
\hline 5 & I have what it takes. & A & B & $\mathrm{C}$ & $\mathrm{D}$ \\
\hline 6 & Interpret threats as opportunities & A & B & C & $\mathrm{D}$ \\
\hline 7 & Get angry and frustrated & A & B & C & $\mathrm{D}$ \\
\hline 8 & Take responsibility for targets & A & B & C & $\mathrm{D}$ \\
\hline 9 & Self-doubt & A & B & $\mathrm{C}$ & $\mathrm{D}$ \\
\hline 10 & Distracted easily & A & B & C & $\mathrm{D}$ \\
\hline 11 & My qualities set me apart. & A & B & C & $\mathrm{D}$ \\
\hline 12 & I give up. & A & B & $\mathrm{C}$ & $\mathrm{D}$ \\
\hline 13 & Under pressure, I can make decisions. & A & B & C & $\mathrm{D}$ \\
\hline 14 & Regain composure & A & B & C & $\mathrm{D}$ \\
\hline
\end{tabular}


Author Query

AQ1: Please provide the upper value. 